Journal of Animal and Veterinary Advances 11 (19): 3544-3549, 2012

ISSN: $1680-5593$

(C) Medwell Journals, 2012

\title{
Rapid Detection of Virulent Salmonella Strains Using Multiplex PCR
}

\author{
${ }^{1} \mathrm{Li}$ Qiu, ${ }^{2} \mathrm{Chao}$ Sun, ${ }^{2} \mathrm{Hu}$ Yang, ${ }^{2} \mathrm{Chunli} \mathrm{Li},{ }^{2} \mathrm{Zhang}$ Feng, ${ }^{2}$ Yahui Zhao, ${ }^{2}$ Xiaoye Liu, ${ }^{2} \mathrm{Rui}$ Wang, \\ ${ }^{2}$ Min Duan, ${ }^{1}$ Xinglong Wang and ${ }^{1}$ Zengqi Yang \\ ${ }^{1}$ College of Veterinary Medicine, ${ }^{2}$ College of Life Science, Northwest A\&F University, \\ 712100 Yangling, Shaanxi Province, China
}

\begin{abstract}
This study aims to establish a rapid and sensitive multiplex PCR Method for Salmonella detection and the differentiation of virulent strains. Four sets of primers that target his J, spvR and fliC were designed and the PCR reaction conditions were then optimized. Based on the detection of reference Salmonella strains and other reference bacterial genera, the PCR Method was able to detect his J, spvR, fliC-c and fliC-i in Salmonella. The minimum detectable DNA concentration of the method is $100 \mathrm{pg}$. The results using the reference strains were consistent with previous research. In addition, this method can also be used in identifying S. typhimurium and S. arizona. Researchers successfully developed a convenient and useful multiplex PCR Method for detecting Salmonella and monitoring virulent strains.
\end{abstract}

Key words: Salmonella, multiplex PCR, virulence detection, strains, reaction, China

\section{INTRODUCTION}

The genus Salmonella is one of the most common causes of food-borne illness worldwide. Salmonella, especially the highly pathogenic strains such as S. enteritidis and S. typhimurium, pose a serious threat to both humans and animals. Salmonella strains are divided into 58 groups based on the $\mathrm{O}$ antigen. Virulent strains usually belong to groups A-F. The $\mathrm{H}$ antigen, an important virulence factor is a flagellum antigen. The Salmonella $\mathrm{H}$ antigen consists of an $\mathrm{H} 1$ phase and an $\mathrm{H} 2$ phase. Together with the $\mathrm{O}$ and $\mathrm{H}$ antigens, Salmonella could be divided into different serotypes. About $>2500$ Salmonella serotypes have been identified through $O$ and $\mathrm{H}$ antigen agglutination tests (Akiba et al., 2011).

Salmonella strains with virulence plasmids show at least a hundred fold stronger pathogenicity than Salmonella strains without these plasmids. Earlier research found that $S$. typhimuriuum, S. abortusovis, S. choleraesuis, S. enteritidis, S. dublin, S. pullorum, $S$. gallinarum, $S$. arizona and $S$. typhi have virulence plasmid (Takeshi et al., 2001; Bessa et al., 2007; Liu et al., 2011). The virulence plasmid genes $s p v R, s p v A$, $s p v B, s p v C$ and $s p v D$ encode the virulence elements of highly pathogenic Salmonella in a highly conserved $10 \mathrm{~kb}$ area and $s p v$ gene especially $s p v R$ gene which can be used as a marker for identifying highly pathogenic Salmonella strains (Libby et al., 1997, 2002; Takeshi et al., 2001; Huang et al., 2005; Bessa et al., 2007; Liu et al., 2006). The hisJ, the histidine transport operon gene is usually used to differentiate Salmonella from other bacterial genera (Cohen at al., 1994; Liu et al., 2011). In addition, $f l i C$, the phase 1 flagellar antigen gene is generally used to identify the $\mathrm{H} 1$ antigen types of Salmonella (Kilger and Grimont, 1993; Dauga et al., 1998; Jamshidi et al., 2010; Liu et al., 2011).

Multiplex Polymerase Chain Reaction (PCR) which simultaneously diagnoses different genes has incomparable advantages over common PCR. Multiplex PCR has been used to detect different pathogens, particularly those that are hard to separate or cultivate (Liu et al., 2011). This research establishes a multiplex PCR Method to diagnose virulent Salmonella rapidly using the $h i s J$, fliC and $s p v R$ genes. The method can be used to detect pathogenic Salmonella strains in food, water and the environment and it can be used to identify S. typhimurium and S. arizona.

\section{MATERIALS AND METHODS}

Bacterial strains and culture conditions: The data of the reference Salmonella bacteria strains and other genus bacteria strains were shown in Table 1 and 2 , respectively. The bacteria were recovered in LB medium and culture in $37^{\circ} \mathrm{C}$. The bacteria in logarithmic phase were used to extract DNA (Salehi et al., 2011; Hu et al., 2011).

DNA extraction: Bacterial DNA was extracted as follows. Briefly, $1 \mathrm{~mL}$ of each bacterial fluid was poured into EP tubes and centrifuged at $8,000 \mathrm{rpm}$ for $5 \mathrm{~min}$. The

Corresponding Author: Zengqi Yang, College of Veterinary Medicine, Northwest A\&F University, 712100 Yangling, P.R. China 
Table 1: The characters of common Salmonella serotypes

\begin{tabular}{|c|c|c|c|c|c|c|}
\hline Salmonella & Groups & $\mathrm{O}$ antigen & $\mathrm{H} 1$ & $\mathrm{H} 2$ & Virulence plasmid & Reference \\
\hline S.paratyphi A & A & $1,2,12$ & $\mathrm{a}$ & $(1,5)$ & - & \\
\hline S. typhimuriuum & $\mathrm{B}$ & $1,4,(5), 12$ & $\mathrm{i}$ & 1,2 & + & This research \\
\hline S. abortusovis & B & 4,12 & c & 1,6 & + & \\
\hline S. typhisuis & $\mathrm{C} 1$ & 6,7 & c & 1,5 & - & \\
\hline S. choleraesuis & $\mathrm{C} 1$ & 6,7 & c & 1,5 & + & This research \\
\hline S. newport & $\mathrm{C}_{2}$ & 6,8 & $\mathrm{e}, \mathrm{h}$ & 1,2 & - & \\
\hline S. kentucky & $\mathrm{C} 3$ & 8,20 & $\mathrm{i}$ & z6 & - & \\
\hline S. typhi & D1 & 9,12 , (vi) & $\mathrm{d}$ & - & + & This research \\
\hline S. enteritidis & D1 & $1,9,12$ & $\mathrm{~g}, \mathrm{~m}$ & $(1,7)$ & + & This research \\
\hline S. dublin & D1 & $1,9,12,(\mathrm{vi})$ & $\mathrm{g}, \mathrm{p}$ & - & + & This research \\
\hline S. pullorum & D1 & 9,12 & - & - & + & This research \\
\hline S. gallinarum & D1 & $1,9,12$ & - & - & + & \\
\hline S. anctum & E1 & 3,10 & $\mathrm{e}, \mathrm{h}$ & 1,6 & - & \\
\hline S. newington & $\mathrm{E} 2$ & 3,15 & $\mathrm{e}, \mathrm{h}$ & 1,6 & - & \\
\hline S. senffenberg & $\mathrm{E} 4$ & $1,3,19$ & $\mathrm{~g},(\mathrm{~s}), \mathrm{t}$ & - & - & \\
\hline S. aberdeen & $\mathrm{F}$ & 11 & $\mathrm{i}$ & 1,2 & - & This research \\
\hline S. worthington & $\mathrm{G} 2$ & $1,13,23$ & $z$ & $1, w$ & - & \\
\hline S. arizona & $\mathrm{G} 2$ & 61 & $1, \mathrm{v}$ & $1,5,7:(\mathrm{z} 57)$ & + & This research \\
\hline
\end{tabular}

0 : Positive or negative; +: Positive; -: Negative

Table 2: The characters of Salmoenlla and non-Salmonella in this study

\begin{tabular}{lccccc} 
Bacteria & his $\mathrm{J}$ & fliC-c & fliC-i & spvR & Source \\
\hline S. typhimurium & + & - & + & + & CVCC-42/85 \\
S. choleraesuis & + & + & - & + & CVCC-50019 \\
S. typhi & + & - & - & + & CVCC-50180 \\
S. enteritidis & + & - & - & + & CVCC-C79-52 \\
S. dublin & + & - & - & + & CVCC-50104 \\
S. pullorum & + & - & - & + & CVCC-50047 \\
S. aberdeen & + & - & + & - & CVCC-50107 \\
S. arizona & - & - & - & + & CVCC-47001 \\
Escherichia coli & - & - & - & - & ATCC-25922 \\
Enterococcus foecalis & - & - & - & - & ATCC-29212 \\
Staphylococcus aureus & - & - & - & - & ATCC-29213 \\
Shigellaflexneri & - & - & - & - & ATCC-12022 \\
Streptococcus agalactiae & - & - & - & - & ATCC-13813 \\
\hline
\end{tabular}

supernatant liquids were discarded and the bacteria were resuspended in $100 \mu \mathrm{L}$ of sterile distilled water. The resuspended bacteria were boiled for $10 \mathrm{~min}$ and then the lysates were centrifuged at $8000 \mathrm{rpm}$ for $5 \mathrm{~min}$. The supernatant liquids were used as templates (Liu et al., 2011; Jeyasekaran et al., 2012).

Primer design: The primers for amplifying his $J$, spvR, fliC-c and flic-i were designed and the sequences are shown in Table 3 . The primers for hisJ which are different from earlier reported PCR primers (Cohen at al., 1994), target a 359 bp DNA fragment. A new set of spvR primers was designed to amplify 789 bp DNA fragment which is different from the primers reported (Mahon and Lax, 1993; Pan and Liu, 2002). Two sets of primers that share the same ups tream primer were used to de tect fliC-c and flic-i.

The co-upstream primer targets the conserved area of fliC and the different downstream primers target variant areas for distinguishing fliC-c and fliC-i (Liu et al., 2006, 2011). The primer design for fliC-c and fliC-i of Salmonalla were observed in Fig. 1.

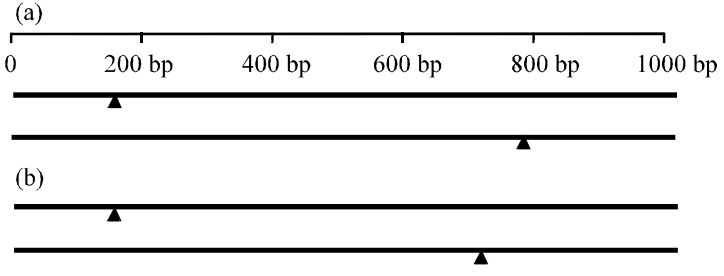

Fig. 1: The primer design for fliC-c and fliC-i of Salmonalla; a) The primer design for fliC-c of Salmonella (623 bp); b) The primer design for fliC-i of Salmonella (537 bp). The fliC-c and fliC-i of Salmonella have the co-upstream primer

Optimal reaction condition: A volume of $30 \mu \mathrm{L}$ PCR reaction system was used. The most suitable reaction concentration of primers, dNTP and DNA template were selected one by one. DNA extracted from the standard $S$. choleraesuis (H1-c) and $S$. typhimurium (H1-i) were used to optimize the reaction conditions for the multiplex PCR. A gradient PCR Method was used to determine the optimum annealing temperature of the multiplex PCR. The amplification products were electrophoresed in $1.5 \%$ agarose gel and observed under UV.

Sensitivity test: A 10 fold serial dilution of the DNA extracted from the mixture of S. choleraesuis (H1-c) and S. typhimurium ( $\mathrm{H1}-\mathrm{i})$ standard strains were used to test the sensitivity of the method. The DNA concentrations were measured by nanodrop. The maximum concentration of the DNA template was $100 \mathrm{ng}$ whereas the minimum was $1 \mathrm{pg}$.

Specificity test: To test the specificity of the multiplex PCR, five non-Salmonella standard strains, namely, Escherichia coli, Enterococcus faecalis, Staphylococcus 
Table 3: Primers sequences and PCR products in this study

\begin{tabular}{|c|c|c|c|c|}
\hline Genes & Primer & Primer sequence & Product size (bp) & References \\
\hline \multirow[t]{2}{*}{ hisJ } & SJF1 & 5'-CGC TCC TAC ATA CGC ACC G-3' & & Liu et al. (2011) \\
\hline & SJR1 & 5'-AGT GCT CAT TGC CGA AGG TC-3' & 359 & \\
\hline \multirow[t]{2}{*}{$s p v R$} & SPF2 & 5'-TGG TGT CTC CCG TTT CTT GG-3' & & Liu et al. (2011) \\
\hline & SPR2 & 5'- CAA ACA GGT TCC TTC AGT ATCGC-3' & 789 & \\
\hline $\mathrm{fliC}$ & SHF1 & 5'-CTC TTC CGG TCT GCG TAT C-3' & & \\
\hline$f l i C-c$ & SHR c & 5'-CA TCA TGG TAT CCA CTG ACA GTC-3' & 623 & Liuetal. $(2006,2011)$ \\
\hline $\mathrm{AliC-i}$ & SHRi & 5'-CCA AGA CCA TTA GCC GAG-3' & 537 & Liuet al. $(2006,2011)$ \\
\hline
\end{tabular}

aureus, Shigella flexneri and Streptococcus agalactiae, were tested. In addition, eight standard Salmonella species, namely, $S$. typhimurium, $S$. choleraesuis, $S$. typhi, S. enteritidis, S. dublin, S. pullorum, S. aberdeen and $S$. arizona were used to check the method.

The five non-Salmonella and eight Salmonella standard species were also used to infect chickens artificially. The tissues were then used to detect the bacteria by the mutiplex PCR assay and the samples were prepared via the Pugliese's Method (Pugliese et al., 2011). The multiplex PCR assay were also evaluated in detecting clinical samples which are collected from local animal farms and food markets and prepared following the method reported by Pugliese et al. (2011) and Bessa et al. (2007). A total of 83 samples were detected by this method.

\section{RESULTS AND DISCUSSION}

Optimal reaction condition: DNA extracted from standard high pathogenic S. choleraesuis (H1-c) and S. typhimurium $(\mathrm{H} 1-\mathrm{i})$ were used to optimize the reaction conditions for multiplex PCR. The $52^{\circ} \mathrm{C}$ annealing temperature was determined from a series of temperatures. At that temperature, the reaction was performed perfectly and the bands were clear when observed under UV light. The optimal concentrations for the primers, the DNA template and the Taq polymerase were selected individually. For the $30 \mu \mathrm{L}$ volume, the optimum conditions were as follows: $1 \mu \mathrm{L}$ of DNA template, $0.5 \mu \mathrm{L}$ of each primer, $3 \mu \mathrm{L}$ of $10 \mathrm{mM}$ dNTP, $3 \mu \mathrm{L}$ of $10 \times$ buffer (with $\mathrm{Mg}^{2+}$ ) and $0.4 \mu \mathrm{L}$ of Taq DNA polymerase. The results under these conditions are displayed in Fig. 2.

Sensitivity test: Serial DNA extraction from $S$. choleraesuis ( $\mathrm{H} 1-\mathrm{c})$ and $S$. typhimurium $(\mathrm{H} 1-\mathrm{i})$ standard strains at maximum dilution (100 ng) was used to test the minimum detectable DNA quality of the method. As shown in Fig. 3, the samples with exceeding $100 \mathrm{pg}$ Salmonella DNA were detected by this multiplex PCR.

Specificity test: To test the specificity of the multiplex PCR, five non-Salmonella and eight standard Salmonella strains were used to check the method. As shown in Fig. 4, the hisJ gene (359 bp) and the $s p v R$ gene (789 bp)

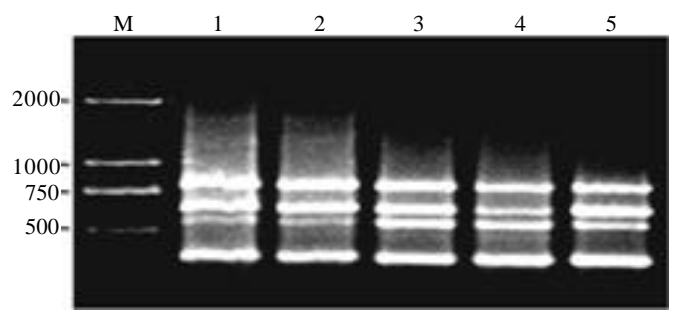

Fig. 2: Optimization of the annealing temperature in the multiplex PCR system. Lane M: DNA marker DL2000; Lane 1: 55; Lane 2: 53.2; Lane 3: 52; Lane 4: 51; Lane 5: 50.2

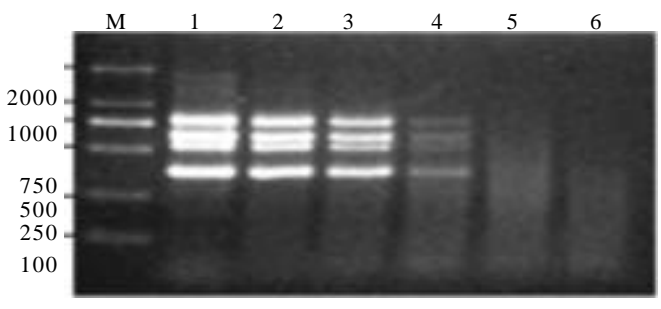

Fig. 3: Sensitivity detection of the primers in the multiplex PCR system. Lane M: DNA marker DL2000; Lane 1: $100 \mathrm{ng}$; Lane 2: $10 \mathrm{ng}$; Lane 3: $1 \mathrm{ng}$; Lane 4: $100 \mathrm{pg}$; Lane 5: 10 pg; Lane 6: $1 \mathrm{pg}$

were successfully detected in seven of the Salmonella strains and the fliC-c gene (623 bp) was detected in $S$. choleraesuis. The $f$ liC-i gene $(537 \mathrm{bp})$ was detected in S. typhimurium and $S$. aberdeen. Four different lengths of DNA fragments were detected from mixed samples of $S$. aberdeen with $S$. choleraesuis and $S$. typhimurium with $S$. choleraesuis. Using the proposed multiplex PCR can easily diagnose the serotype of S. arizona and $S$. typhimurium can be easily determined simultaneously. The detection results for all other bacterial genera were negative.

Samples detection: The results of the tissue samples collected from the artificially infected samples (Fig. 4) and the clinical samples demonstrate the specificity and effective of the multiplex PCR for detecting tissue samples. 


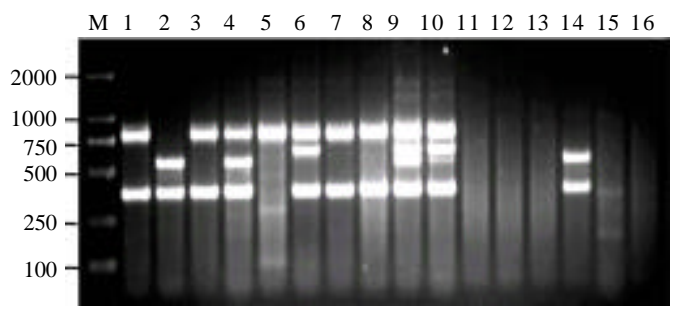

Fig. 4: Specificity detection of the primers in the multiplex PCR system. Lane M: DNA marker DL2000; Lane 1: S. enteritidis, Lane 2: S. aberdeen; Lane 3: S. typhi; Lane 4: S. typhimuriuum; Lane 5: S. arizona; Lane 6: S. choleraesuis; Lane 7: S. pullorum; Lane 8: S. dublin; Lane 9: $S$. aberdeen and $S$. choleraesuis; Lane 10: S. typhimuriuum and S. choleraesuis; Lane 11: Escherichia coli; Lane 12: Shigella flexneri; Lane 13: Enterococcus faecalis, Lane 14: S. aberdeen and Escherichia coli; Lane 15: Staphylococcus aureus; Lane 16: Streptococcus agalactiae

About 83 clinical samples collected from farms and food markets were tested using the proposed method. Up to 32 samples were contaminated with different Salmonella strains. S. typhimurium and $S$. choleraesuis were the major contaminants. The results of multiplex PCR were confirmed by agglutination tests and biochemical tests.

Multiplex PCR primer design: To find specific target sequences for designing multiplex PCR primers, the homology of his J, spvR, fliC-c and fliC-i from different Salmonella strains were analyzed using the Blast and ClustalW Software. The target gene fragments of the primers should at least be $50 \mathrm{bp}$ long with high specificity and accuracy. Researchers found a set of primers that fulfilled the requirements. In addition, to reduce the primer concentration, one of the most important factors that affect the results of multiplex PCR, researchers designed a set of primers for flic-c and fliC-i that share the same upstream primer. To evaluate the primers further, researchers used the PCR primer design system Mpprimer (http://biocompute.bmi.ac.cn/MPprimer/) (Shen et al., 2010) and the multiplex PCR primer specific assessment system MFEprimer (http://biocompute.bmi.ac.cn/ MFEprimer/) (Qu et al., 2009) (Fig. 5).

Multiplex PCR for different virulent Salmonella strains: Not all Salmonella are pathogenic but differentiating pathogenic strains through traditional animal challenge tests is difficult. PCR is one of most sensitive and rapid methods for test pathogens. Mahon and Lax (1993) pioneered a way to differentiate virulent Salmonella using

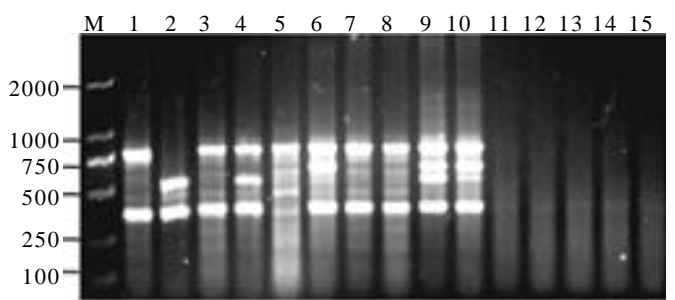

Fig. 5: Diagnosis of meat by artificial infection standard Salmonella strains and non-Salmonella standard strains using the multiplex PCR assay. Lane M: DNA marker DL2000; Lane 1: S. enteritidis; Lane 2: S. aberdeen; Lane 3: S. typhi; Lane 4: S. typhimuriuum; Lane 5: S. arizona; Lane 6: S. choleraesuis; Lane 7: S. pullorum; Lane 8: $S$. dublin; Lane 9: $S$. aberdeen and $S$. choleraesuis; Lane 10: S. typhimuriuum and S. choleraesuis; Lane 11: Escherichia coli; Lane 12: Shigella flexneri; Lane 13: Enterococcus faecalis; Lane 14: Staphylococcus aureus; Lane 15: Streptococcus agalactiae

PCR by testing for the $s p v R$ gene. Researchers improved on this research and established a multiplex PCR that can be use for detecting salmonella detection and for differentiating virulent strains. The reference Salmonella species $S$. arizona was confirmed by Libby et al. (2002) to express spvR using Transverse Alternating-Field Electrophoresis (TAFE) and an $s p v$ gene probe. The $s p v$ gene of $S$. typhi was identified by Huang et al. (2005) using PCR and probes.

The results reflect the same situation; multiple detection of one sample showed the reliable repeatability of the method. Virulent Salmonella strains were simultaneously discriminated from other bacterial genera and nonpathogenic Salmonella. Therefore, this method is useful and convenient in detecting pathogenic Salmonella in food, water and environment samples.

Multiplex PCR for differentiating certain Salmonella serotypes: The proposed multiplex PCR Method rapidly and effectively detected Salmonella stains and their virulence as well as differentiated S.typhimurium and $S$. arizona. S. arizona is the only species that expresses the $s p v R$ gene but not hisJ. S. typhimurium is the only species that expresses both spvR and fliC-i. Based on the electrophoretic pattern, S. typhimurium and $S$. arizona could be differentiated from other Salmonella strains. 


\section{CONCLUSION}

Researchers successfully established a multiplex PCR Method for detecting Salmonella and differentiating virulent Salmonella strains by detecting hisJ, spvR, $f l i C-c$ and $f l i C-i$ genes at a minimum detectable DNA concentration of $100 \mathrm{pg}$. This method can also be used in identifying S. typhimurium and S. arizona. Researchers provide a useful and convenient method for detecting and monitoring Salmonella in food, water and the environment.

\section{ACKNOWLEDGEMENTS}

The research was supported by Shaanxi Province Sci-Tec Project (2010K01-28) and China National Animal Science Experimental Teaching Demonstration Project. Acknowledge Dr. Yang B.W. for providing the non-Salmonella standard strains.

\section{REFERENCES}

Akiba, M., M. Kusumoto and T. Iwata, 2011. Rapid identification of Salmonella enteric serovars, Typhimurium, Choleraesuis, Infantis, Hadar, Enteritidis, Dublin and Gallinarum, by multiplex PCR. J. Microbiol. Methods, 85: 9-15.

Bessa, M.C., G.B. Michael, N. Canu, C.W. Canal, M. Cardoso, W. Rabsch and S. Rubino, 2007. Phenotypic and genetic characterization of Salmonella enteric subsp. enterica serovar Typhimurium isolated from pigs in Rio Grande do Sul, Brazil. Res. Vet. Sci., 83: 302-310.

Cohen, N.D., D.E. Wallis, H.L. Neibergs, A.P. McElroy and E.D. McGruder et al., 1994. Comparison of the polymerase chain reaction using genus-specific oligonucleotide primers and microbiologic culture for the detection of Salmonella in drag-swabs from poultry houses. Poult. Sci., 73: 1276-1281.

Dauga, C., A. Zabrovskaia and P.A.D. Grimont, 1998. Restriction fragment length polymorphism analysis of some flagellin genes of Salmonella enteric. J. Clin. Microbiol., 36: 2835-2843.

Hu, Q.H., J. Tu, X.G. Han, Y.Y. Zhu, C. Ding and S.Q. Yu, 2011. Development of multiplex PCR assay for rapid detection of Riemerella anatipestifer, Escherichia coli and Salmonella enterica simultaneously from ducks. J. Microbiol. Methods, 87: 64-69.
Huang, R., S.Y. Wu, X.G. Zhang and Y.Y. Zhang, 2005. Molecular analysis and identification of virulence gene on pRST98 from multi-drug resistant Salmonella typhi. Cellular and Mole. Immunol., 2: 136-140.

Jamshidi, I., G.A. Kalidari and M. Hedayati, 2010. Isolation and identification of Salmonella Enteritidis and Salmonella Typhimurium from the eggs of retail stores in Mashhad, Iran using conventional culture method and multiplex PCR assay. J. Food Safety, 30: 558-568.

Jeyasekaran, G., K.T. Raj, R.J. Shakila, A.J. Thangarani and D.R. Sukumar, 2012. Detection of Salmonella enterica serovars in shrimps in eight hours by multiplex PCR assay. Ann. Microbiol., 62: 225-231.

Kilger, G. and P.A. Grimont, 1993. Differentiation of Salmonella phase 1 flagellar antigen types by restriction of the amplified $f l i \mathrm{C}$ gene. J. Clin. Microbiol., 31: 1108-1110.

Libby, S.J., L.G. Adams, T.A. Ficht, C. Allen and H.A. Whitford et al., 1997. The spv genes on the Salmonella dublin virulence plasmid are required for severe Enteritis and systemic infection in the natural host. Infection Immunity, 65: 1786-1792.

Libby, S.J., M. Lesnick, P. Hasegawa, M. Kurth, C. Belcher, J. Fierer and D.G. Guiney, 2002. Characterization of the $s p v$ locus in Salmonella enteric serovar Arizona. Infection Immunity, 70: 3290-3294.

Liu, H.W., H. Zhang, Q.H. Wang, X.Y. Liu, R. Wang and L. Qiu, 2011. Rapid test of Salmonella strain with high pathogenicity. Chin. J. Vet. Sci., 31: 378-383 (In Chinese).

Liu, H.W., L.N. Ma, A.G. Guo and L. Qiu, 2006. Rapid detection of Salmonella with familiar special phase of $\mathrm{H}$ antigen. Acta. Agric. Boreali-Occidentalis Sinica, 15: 38-41, (In Chinese).

Mahon, J. and A. Lax, 1993. A quantitative polymerase chain reaction method for the detection in avian faeces of Salmonella carrying the $s p v R$ gene. Epidemiol. Infect., 111: 455-464.

Pan, T.M. and Y.J. Liu, 2002. Identification of Salmonella enteritidis isolated by polymerase chain reaction and multiplex polymerase chain reaction. J. Microbiol. Immunol. Infect., 45: 147-151.

Pugliese, N., E. Circella, C. Pazzani, A. Pupillo and A. Camarda, 2011. Validation of a seminested PCR approach for rapid detection of Salmonella enteric subsp. enterica serovar Gallinarum. J. Microbiol. Methods, 85: 22-27. 
Qu, W.B., Z.Y. Shen, D.S. Zhao, Y. Yang and C.G. Zhang, 2009. MFEprimer: Multiple Factor Evaluation of the specificity of PCR primers. Bioinformatics, 25: $276-278$

Salehi, T.Z., O. Madadgar, S. Naserli, B.N. Fasaei, M.M. Ghafari and I.A. Tamai, 2011. Detection of sef14, sef1 7 and sef21 fimbrial virulence genes of by multiplex PCR. J. Anim. Vet. Adv., 10: 1421-1426.
Shen, Z.Y., W.B. Qu, W. Wang, Y.M. Lu and Y.H. Wu et al., 2010. MPprimer: A program for reliable multiplex PCR primer design. BMC Bioinformatics, Vol. 11.

Takeshi, H., O. Nobuhiko, N. Noriko, K. Takatoshi and D. Hirofumi, 2001. Complete DNA sequence and comparative analysis of the 50-kilobase virulence plasmid of Salmonella enterica serovar Choleraesuis. Infection Immunity, 69: 2612-2620. 